\title{
Development of green insulation boards from kenaf fibres part 1: development and characterization of mechanical properties
}

\begin{abstract}
The purpose of this study was to develop effective green insulation boards fabricated from polyurethane (PU) reinforced with Kenaf fibres. Biocomposites having three different weight contents (40/60, 50/50 and 60/40 Kenaf / PU weight \%) were manufactured. A fourth type was made from 60/40 NaOH-treated Kenaf / PU weight \%. The results show that the elastic properties increased with Kenaf fibre content. The optimal performance was observed at a weight of $50 \%$ Kenaf fibres. In addition, kenaf fibres treated with $\mathrm{NaOH}$ exhibited significantly improved mechanical properties.
\end{abstract}

Keyword: Biocomposites; Natural materials; Polyurethane 